Check for updates

Cite this: J. Mater. Chem. A, 2019, 7, 10325

Received 21st January 2019 Accepted 22nd March 2019

DOI: 10.1039/c9ta00789j

rsc.li/materials-a

\title{
A novel method for fabrication of high-flux zeolite membranes on supports with arbitrary geometry $\dagger$
}

\begin{abstract}
Liang Yu, (D) * Allan Holmgren and Jonas Hedlund
A novel procedure for the preparation of high-flux zeolite membranes was developed. This method relies on rendering the support hydrophobic, and thereby protected from the synthesis mixture and invasion of the support pores, while the cationic polymer on the surface still allowed deposition of zeolite seeds. Both high-flux MFI and CHA zeolite films were grown on both discs and tubular supports, which illustrates the applicability of the method to arbitrary membrane geometries. Typically, MFI disc membranes showed a very high $\mathrm{CO}_{2}$ permeance of $85 \times 10^{-7} \mathrm{~mol} \mathrm{~m}{ }^{-2} \mathrm{~s}^{-1} \mathrm{~Pa}^{-1}$ and a $\mathrm{CO}_{2} / \mathrm{H}_{2}$ separation selectivity of 56 at $278 \mathrm{~K}$ and $\mathrm{CHA}$ disc membranes showed a very high $\mathrm{CO}_{2}$ permeance of $79 \times 10^{-7} \mathrm{~mol} \mathrm{~m}^{-2} \mathrm{~s}^{-1} \mathrm{~Pa}^{-1}$ and a $\mathrm{CO}_{2} / \mathrm{CH}_{4}$ separation selectivity of 76 at $249 \mathrm{~K}$. As the method is applicable to supports with complex geometries, it is suitable for preparation of membranes for industrial applications.
\end{abstract}

\section{Introduction}

Membranes with high permeance and selectivity are of great interest for separation of gas mixtures, both from scientific and industrial points of view. Compared with other types of membranes, for instance polymeric membranes, microporous zeolite membranes with well-defined pore size are anticipated to provide a combination of high permeance and high selectivity for a wide range of applications. High permeance can be achieved for zeolite membranes provided they possess thin films and low mass transfer resistance in the porous support.

Zeolites are crystalline aluminosilicate materials with a welldefined pore size between 3 and $13 \AA$ and high thermal and chemical stability. Zeolite membranes can be used to separate a variety of gas molecules based on pore size and affinity differences with the molecules. For instance, an MFI membrane with a pore size of $5.5 \AA$ is a promising candidate for separation of synthesis gas mainly containing $\mathrm{CO}_{2}(3.3 \AA)$, $\mathrm{CO}(3.7 \AA)$ and $\mathrm{H}_{2}(2.8 \AA)$, based on the strong affinity between $\mathrm{CO}_{2}$ and the zeolite. ${ }^{1}$ For this separation, we have reported highly permeable and selective membranes, ${ }^{\mathbf{1 - 3}}$ albeit prepared by procedures not suited for supports with complex geometries. Zeolite CHA membranes with a pore size around $3.7 \AA$ show high performance for separation of biogas and natural gas mixtures that mainly contain $\mathrm{CO}_{2}$ and $\mathrm{CH}_{4}(3.8 \AA)$ based on molecular sieving. ${ }^{\mathbf{4 - 6}}$ We have recently reported highly permeable and selective CHA membrane discs prepared by a newly developed

Chemical Technology, Luleå University of Technology, SE-971 87 Luleå, Sweden. E-mail: liang.yu@ltu.se; Fax: +46 920491199; Tel: +46920493002

$\dagger$ Electronic supplementary information (ESI) available: Permporometry patterns of tubular MFI membranes and single gas permeances of tubular CHA membranes. See DOI: 10.1039/c9ta00789j method. ${ }^{7}$ So far, however, most of the other reported CHA membranes have high selectivity but low permeance. In $\mathrm{CO}_{2} /$ $\mathrm{CH}_{4}$ separation, most of the reported zeolite membranes with small pore size, including CHA and DDR display high selectivity, e.g. 100-200, but very low $\mathrm{CO}_{2}$ permeance, viz. 0.4 to $5 \times$ $10^{-7}$ mol m${ }^{-2} \mathrm{~s}^{-1} \mathrm{~Pa}^{-1} .^{8-12}$ Zeolite membranes with larger pore size, like FAU and MFI, display slightly higher permeance (7.5 to $\left.9 \times 10^{-7} \mathrm{~mol} \mathrm{~m}{ }^{-2} \mathrm{~s}^{-1} \mathrm{~Pa}^{-1}\right)$, but separation selectivities only in the range of 5-40. ${ }^{13-15}$ To be competitive, zeolite membranes must probably display much higher permeance than polymeric membranes due to the higher price per membrane area for ceramic zeolite membranes. We have shown that MFI zeolite membranes with a $\mathrm{CO}_{2}$ permeance of $78 \times 10^{-7} \mathrm{~mol} \mathrm{~m}^{-2} \mathrm{~s}^{-1}$ $\mathrm{Pa}^{-1}$ may compete economically with polymeric membranes. ${ }^{16} \mathrm{To}$ arrive at high permeance, a thin zeolite film is of course necessary. However, it is also important to use a highly permeable support such as a graded alumina support. Such supports may comprise a 10 to $30 \mu \mathrm{m}$ thick top layer with $100 \mathrm{~nm}$ pores, which is in turn supported by a 1-3 mm thick base layer with a pore size of $3 \mu \mathrm{m}$. The porosity in both layers is as high as about $40 \%$. To maintain the high permeability of the support, it is crucial to prevent deposition of zeolite or species from the synthesis mixture in the support pores, a phenomenon we denote as "invasion". ${ }^{17}$ We have shown that invasion can be minimized by masking the support e.g. with PE wax. ${ }^{18}$ In addition, as a masked support will be protected from the synthesis mixture, the mechanical strength of the support will be maintained, and leaching of e.g. aluminium from alumina supports and subsequent incorporation into the zeolite film will be minimized.

Hydrophobic zeolite membranes, i.e. with high $\mathrm{Si} / \mathrm{Al}$ ratios, are of great interest in industrial applications since industrial gas mixtures usually contain water vapour. Consequently, 
zeolite membranes with high $\mathrm{Si} / \mathrm{Al}$ ratios are of great industrial importance. The masking technique developed by our group has proved to be an effective method to prepare high-flux zeolite membranes with no or only little invasion. The prepared MFI membranes with a high $\mathrm{Si} / \mathrm{Al}$ ratio of about 139 showed high permeance and selectivity in many separation systems, such as hydrocarbon isomer separation, upgrading of syngas, separation of alcohol/water mixtures by pervaporation, hydrocarbon recovery etc. ${ }^{19-23}$ However, the membrane preparation method is time consuming [WO 00/53298] and very difficult to apply on multi-channel tubular supports needed in industrial applications. An alternative masking procedure has been reported by Yan et $a .^{24}$ In this method, a mixture of furfuryl alcohol and tetraethyl orthosilicate was polymerized in the pores of an $\alpha$ $\mathrm{Al}_{2} \mathrm{O}_{3}$ support followed by carbonization prior to zeolite synthesis. The carbonized polymer was supposed to work as a barrier to reduce the amount of siliceous species in the support in order to enable the preparation of high flux and hydrophobic zeolite membranes. ${ }^{24}$ However, an obvious disadvantage with this method is the silica that formed from the tetraethyl orthosilicate remaining in the pores, and the observed permeance was not as high as our MFI membranes and calcination is necessary to remove the carbonized polymer.

Therefore, a new and effective masking method that is suitable for porous supports with complex geometry and also easy to apply is of utmost importance. Our recently reported highly permeable and selective CHA membrane discs have preliminarily demonstrated the potential of a new method developed by our group. ${ }^{7}$ In the present work, this method is described in detail for the first time and the preparation of high flux MFI and CHA discs and single channel tubular membranes with high $\mathrm{Si} / \mathrm{Al}$ ratios is demonstrated. The separation performances of MFI and CHA membranes for separation of $\mathrm{CO}_{2}$ from $\mathrm{CO}_{2} / \mathrm{H}_{2}$ and $\mathrm{CO}_{2} / \mathrm{CH}_{4}$ mixtures are presented.

\section{Experimental}

\section{Membrane preparation}

The preparation procedure is summarized in Fig. 1. The membranes were synthesized on porous graded $\alpha$-alumina discs and tubes (Fraunhofer IKTS, Germany). The discs had

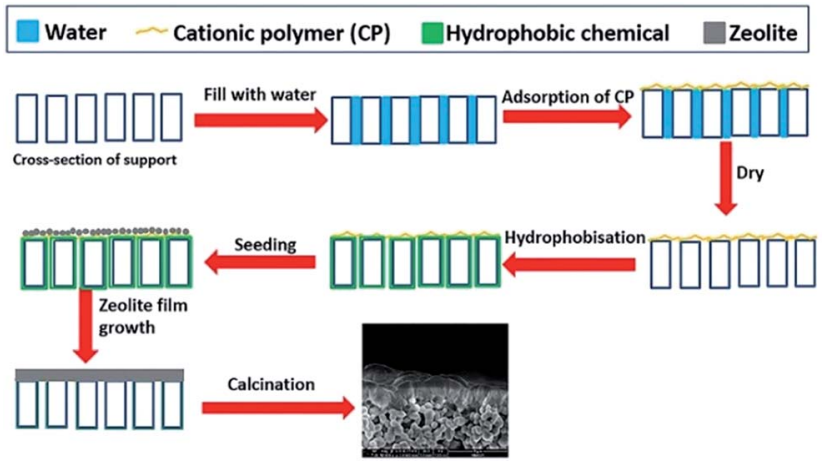

Fig. 1 Scheme describing the steps of the new method. The cationic polymer is denoted as "CP". a diameter of $25 \mathrm{~mm}$ and a $30 \mu \mathrm{m}$ thick top layer onto which the membrane was synthesized. The pore size of the top layer was $100 \mathrm{~nm}$. The tubular supports had a length of $100 \mathrm{~mm}$, an inner diameter of $7 \mathrm{~mm}$, and an outer diameter of $10 \mathrm{~mm}$. The membrane was synthesized on a $30 \mu \mathrm{m}$ thick inner layer with a pore size of $100 \mathrm{~nm}$. All work was carried out in a laminar flow bench using filtered solutions. Prior to use, the supports were calcined at $500{ }^{\circ} \mathrm{C}$ for $6 \mathrm{~h}$ to remove any possible organic contamination. Subsequently, the supports were rinsed with filtered deionized water and then placed in a filtered $(0.8 \mu \mathrm{m}) 1.0$ wt $\%$ aqueous cationic polymer (ATC 4150, poly(dimethylamineco-epichlorohydrin-co-ethylenediamine), $50 \mathrm{wt} \%$ in $\mathrm{H}_{2} \mathrm{O}, M_{\mathrm{w}}=$ $75000 \mathrm{~g} \mathrm{~mol}^{-1}$, Eka Chemicals AB, Sweden) solution with a pH of 9.0, for 20 minutes. The supports were then rinsed with a $0.1 \mathrm{M}$ aqueous $\mathrm{NH}_{3}$ solution to remove excess cationic polymer and subsequently dried at $120{ }^{\circ} \mathrm{C}$ for $2.5 \mathrm{~h}$. The supports were then immersed for $60 \mathrm{~min}$ in a filtered $2.5 \mathrm{wt} \%$ ethanol solution of the hydrophobic chemical $(1 \mathrm{H}, 1 \mathrm{H}, 2 \mathrm{H}, 2 \mathrm{H}$-perfluorodecyltriethoxysilane $97 \%$, Sigma-Aldrich). After rinsing with ethanol to remove the excess hydrophobic chemical, the supports were dried at $120{ }^{\circ} \mathrm{C}$ for $1.5 \mathrm{~h}$ and then immersed in a filtered $1 \mathrm{wt} \%$ seed solution for $15 \mathrm{~min}$. After seeding, the supports were rinsed with a filtered $(0.1 \mu \mathrm{m}) 0.1 \mathrm{M}$ aqueous $\mathrm{NH}_{3}$ solution to remove excess seed crystals. The seeded supports were hydrothermally treated for 55 hours at $88^{\circ} \mathrm{C}$ in a synthesis mixture with a molar composition of $3 \mathrm{TPAOH}: 25 \mathrm{SiO}_{2}: 1500 \mathrm{H}_{2} \mathrm{O}: 100 \mathrm{EtOH}$. After cooling, the samples were rinsed in a $0.1 \mathrm{M}$ aqueous ammonia solution and calcined at $500{ }^{\circ} \mathrm{C}$ for $6 \mathrm{~h}$ using a heating rate of $0.2{ }^{\circ} \mathrm{C}$ $\min ^{-1}$ and a cooling rate of $0.3{ }^{\circ} \mathrm{C} \min ^{-1}$. For CHA membranes, an identical masking procedure was used. The molar composition of the synthesis gel for growth of CHA films was $1.0 \mathrm{SiO}_{2}: 1.4 \mathrm{TMAdaF}: 9.4 \mathrm{H}_{2} \mathrm{O}$. The aged gel was poured in a PTFE-lined autoclave $(30 \mathrm{ml})$ in which the seeded discs were placed at the bottom of the autoclave with the seeded side downwards. Film growth was carried out under static conditions at $160{ }^{\circ} \mathrm{C}$ for $18 \mathrm{~h}$. The membranes were rinsed with a $0.1 \mathrm{M}$ aqueous $\mathrm{NH}_{3}$ solution and dried at room temperature for two days. Finally, the membranes were calcined at $480{ }^{\circ} \mathrm{C}$ for $12 \mathrm{~h}$ to remove the organic template. A heating rate of $0.2{ }^{\circ} \mathrm{C} \mathrm{min}{ }^{-1}$ and a cooling rate of $0.3{ }^{\circ} \mathrm{C} \mathrm{min}{ }^{-1}$ were used. Membranes prepared on the inner surface of tubular supports underwent the same masking procedure.

\section{Characterisation}

Contact angle measurements of the masked supports were performed using a Fibro 1121/1122 DAT-Dynamic Absorption and Contact Angle Tester equipped with a CCD camera. The contact angle was measured by applying a $4.0 \mu \mathrm{L}$ droplet of distilled water onto the masked as well as seeded $\alpha$-alumina support surface. This was accomplished using the feed system and drop applicator of the DAT instrument. The contact angle from four different locations on the tested surface was analysed and an average value of the contact angle after equilibrium (1 second) was calculated. The structure of the zeolite crystals and films was determined by X-ray diffraction (XRD) using 
a PANalytical Empyrean diffractometer equipped with a Cu LFF HR X-ray tube and a PIXcel3D detector. During the measurement, the irradiated length was fixed to be $1 \mathrm{~mm}$ using an automatic variable divergence slit. An FEI Magellan 400 field emission XHR-SEM was used to investigate the morphology and microstructure of the crystals and membranes. The samples were investigated without any coating.

\section{Single gas and mixed-gas separation experiments}

Single gas permeation experiments of He for MFI and CHA membranes at room temperature were carried out using 1.8 bar (absolute) feed pressure and atmospheric permeate pressure directly after calcination. A single gas He permeation experiment for CHA membranes was carried out before calcination using 6 bar (absolute) feed pressure and atmospheric permeate pressure.

For separation experiments, disc membranes were mounted in stainless steel cells using graphite gaskets (Eriks, the Netherlands) for sealing. Then, the membrane was dried in a flow of helium at $300{ }^{\circ} \mathrm{C}$ for $6 \mathrm{~h}$ with a heating rate of $1^{\circ} \mathrm{C} \mathrm{min}{ }^{-1}$ and subsequently left to cool to room temperature. Sub-ambient membrane temperatures were achieved by placing the membrane cell in a refrigerated silicon oil bath. Permeation of gas mixtures was performed in a continuous flow mode. Equimolar gas mixtures of $\mathrm{CO}_{2} / \mathrm{H}_{2}$ and $\mathrm{CO}_{2} / \mathrm{CH}_{4}$ were employed to evaluate the separation performance of MFI and CHA membranes, respectively. The gas mixtures were fed to the membranes from gas cylinders containing pure gases. The desired flow rate was achieved by using mass flow controllers and the retentate pressure was controlled using a back pressure regulator. The pressure on both sides of the membrane was monitored with pressure gauges. The total feed pressures were 1000 and $900 \mathrm{kPa}$ for the MFI membrane and the CHA membrane, respectively, and the total volumetric flow rate was $10 \mathrm{Nl} \mathrm{min}{ }^{-1}$ for disc membranes and $40 \mathrm{Nl} \mathrm{m^{-1 }}$ for tubular membranes. The permeate was kept at atmospheric pressure and no sweep gas was used. The permeate flow was measured using a drum-type gas meter (Ritter Apparatebau GmbH), and the composition of feed and permeate streams was analysed using a GC (490 Micro GC, Agilent).

\section{Results and discussion}

As shown in Fig. 1, first, the support is filled with water. In the second step, a cationic polymer is adsorbed on the outer surface of the support. In the next steps, the support is dried and the pores are subsequently filled with a solution of a hydrophobic chemical, see Fig. 2.

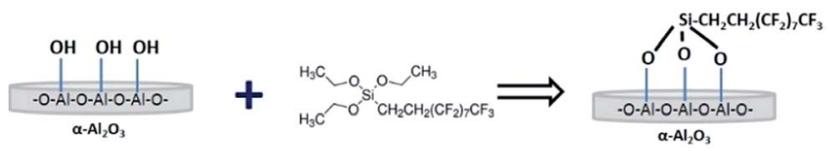

Fig. 2 Scheme describing the hydrophobisation step, i.e. the reaction between the hydrophobic chemical and hydroxyl groups on the surface of the $\alpha$-alumina support.
As schematically shown in Fig. 2, the hydrophobic chemical reacts with $\mathrm{OH}$-groups on the $\alpha$-alumina surface, and consequently the entire porous support becomes hydrophobic. In the next step, seeds are adsorbed onto the cationic polymer. Following this step, the seeded hydrophobic support is hydrothermally treated for growth of a zeolite film. Finally, the membrane is calcined if necessary in order to remove organic template molecules from the zeolite pores. This step may be omitted if the zeolite film is grown without using organic template molecules. More details are given in the Experimental part.

As shown in Fig. 3a, the support was hydrophobic before seeding, and the contact angle of the hydrophobic support coated with cationic polymer was ca. $122^{\circ}$. Fig. 4a shows a monolayer of $50 \mathrm{~nm}$ MFI seeds adsorbed at the hydrophobic support. The seed layer is evenly deposited throughout the entire support surface. The contact angle decreased to $\mathrm{ca} .94^{\circ}$ after seeding (Fig. 3b), which is ascribed to the hydrophilicity of the MFI seeds and the high concentration of seeds on the surface. Fig. 4b shows a top view SEM image of the as-synthesized MFI membrane. The film was continuous, and no pinholes and defects could be observed by SEM. The crosssection of the membrane shown in Fig. 4c indicated an even film thickness of about $400 \mathrm{~nm}$. In addition, the support was completely open with no invasion. Conversely, the support of a membrane prepared without any masking was severely invaded (red framed part in Fig. 4d). Moreover, the electrostatic field caused by the cationic polymer promoted the adsorption of negatively charged seed crystals. Without the cationic polymer, no seeds are attached and accordingly, it is not possible to grow a membrane.

The XRD pattern of an as-synthesized MFI membrane (Fig. 5) shows that the film comprised only the MFI phase, i.e. with no presence of other crystalline phases. The intensity of the peaks

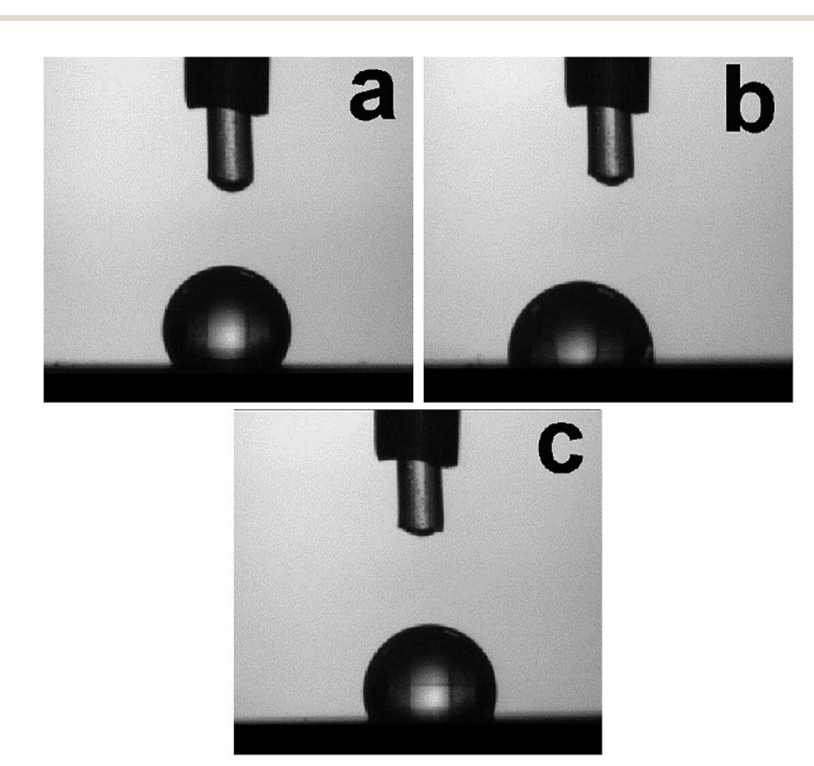

Fig. 3 Examples showing a hydrophobic $\alpha$-alumina disc support before seeding (a), and after seeding with MFI seeds (b) and Si-CHA seeds (c) 


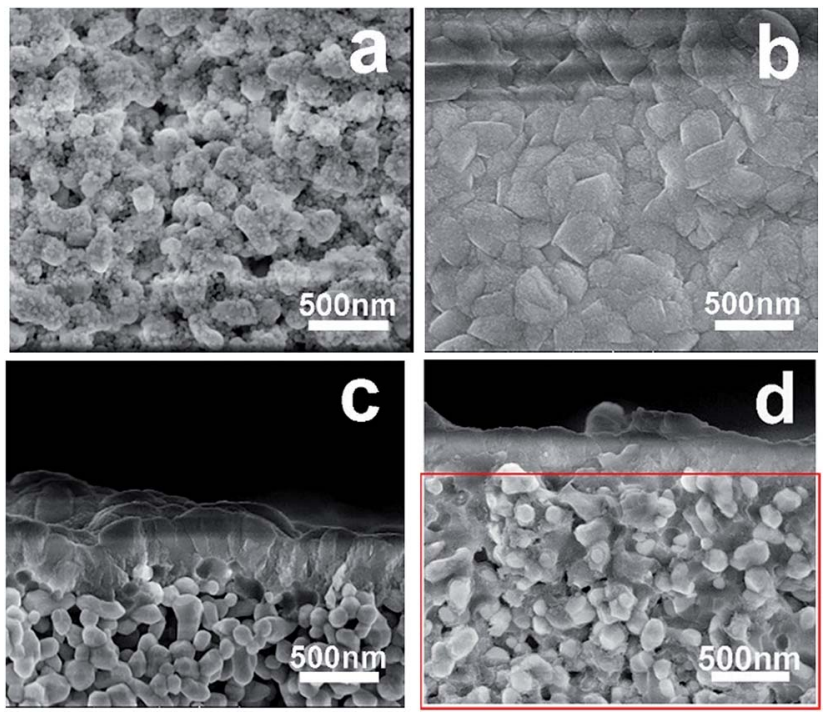

Fig. 4 SEM images of the MFI seed layer (a), top-view (b) and crosssection (c) of an as-synthesised MFI membrane and the MFI membrane prepared without support masking (d).
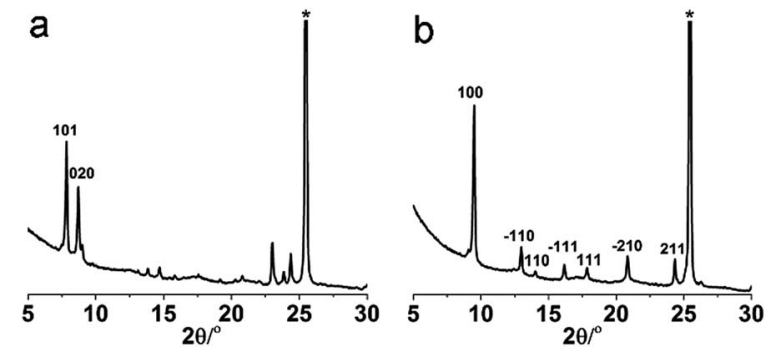

Fig. 5 The XRD patterns of a MFI (a) and a CHA (b) membrane supported on porous $\alpha$-alumina discs. Reflections emanating from the zeolite are indexed and the reflection from the $\alpha$-alumina support is marked with an asterisk.

from MFI zeolite is weak, due to the thickness of the thin film. The $\mathrm{Si} / \mathrm{Al}$ ratio of the MFI membrane was estimated by EDS to be 152, which is higher than that (139) of MFI membranes prepared by the old masking method. ${ }^{19}$ The higher Si/Al ratio indicated that the new masking method could protect the support from synthesis mixture more efficiently.

The single gas He permeance of the MFI membrane prepared by the new method was around $78 \times 10^{-7} \mathrm{~mol} \mathrm{~m}^{-2} \mathrm{~s}^{-1}$ $\mathrm{Pa}^{-1}$ at a feed pressure of 1.8 bar and a permeate pressure of 1 bar at room temperature.

The $n$-hexane/helium adsorption-branch permporometry method was employed to evaluate the quality of the MFI membrane and the permporometry pattern is shown in Fig. 6. The details of the method have been reported previously. ${ }^{25,26}$ As the relative pressure of $n$-hexane was increased from 0 to 0.025 , the zeolite pores and micropore defects smaller than about 1.05 $\mathrm{nm}$ were blocked ${ }^{25}$ and the helium permeance decreased dramatically by $99.7 \%$. When the relative pressure of $n$-hexane was increased to 0.8 , the helium permeance decreased further to $0.1 \%$ of the initial permeance. This indicates that the

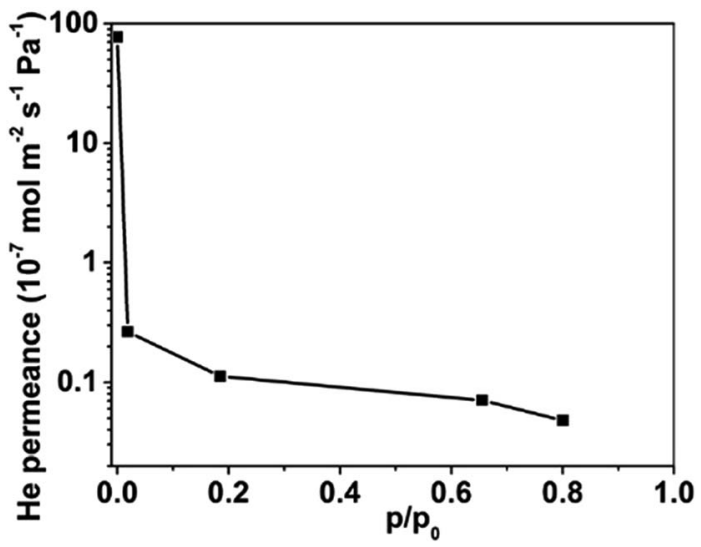

Fig. 6 Adsorption branch He permporometry pattern of a zeolite MFI membrane using $n$-hexane as the adsorbate. The membrane was prepared on a porous $\alpha$-alumina disc using the new preparation method.

membrane is of very high quality with no large defects in accordance with the SEM observations.

The membrane had a $\mathrm{CO}_{2}$ permeance of $85 \times 10^{-7} \mathrm{~mol} \mathrm{~m}^{-2}$ $\mathrm{s}^{-1} \mathrm{~Pa}^{-1}$ and displayed a $\mathrm{CO}_{2} / \mathrm{H}_{2}$ separation selectivity of 56 at $278 \mathrm{~K}$ for separation of an equimolar $\mathrm{CO}_{2} / \mathrm{H}_{2}$ gas mixture at a feed pressure of 10 bar. The separation selectivity is similar to that of the best membranes prepared using our old method ${ }^{\mathbf{1 6}}$ but the $\mathrm{CO}_{2}$ permeance was higher. In addition, the $\mathrm{CO}_{2}$ permeance was significantly higher than that reported for MFI or other zeolite membranes by other groups as summarized in Table $1 .^{27-33}$ The high permeance is a result of a thin zeolite film and a completely open and non-invaded graded support as well as the drying procedure. As reported for polymeric membranes, the separation performance could be affected by the drying process due to the change of the polymer structure at high temperature. ${ }^{34-36}$ However, for thermally stable zeolite membranes, the structure is not affected. Moreover, the high Si/ $\mathrm{Al}$ ratio indicated that the MFI membranes prepared by the new method have great potential in industrial gas separation applications.

In order to demonstrate the wide applicability of the method, Si-CHA membranes were prepared as well. Si-CHA nanocrystals with a size ranging from 70 to $200 \mathrm{~nm}$ were employed as seeds. ${ }^{37}$ The masking procedure was identical to the procedure for preparation of MFI membranes. A uniform and dense monolayer of Si-CHA seeds is illustrated in Fig. 7a. After seeding, the support was still hydrophobic with a contact angle around $111^{\circ}$ as shown in Fig. 3c. The slight decrease of the contact angle is likely due to the high concentration of attached hydrophilic SiCHA seeds.

The XRD pattern of an as-synthesized CHA membrane (Fig. 5b) confirms the purity of the CHA crystalline phase, with no presence of other crystalline phases. The non-calcined assynthesized CHA membranes contain TMAda ( $N, N, N$-trimethyl1-adamant ammonium) as template molecules blocking the zeolite pores. Accordingly, essentially defect-free membranes should be nearly impermeable to any gas before the template is removed by calcination. Five CHA membrane discs prepared in 
Table 1 Typical performance of zeolite membranes for separation of $\mathrm{CO}_{2} / \mathrm{H}_{2}$ and $\mathrm{CO}_{2} / \mathrm{CH}_{4}$ mixtures

\begin{tabular}{|c|c|c|c|c|c|c|c|}
\hline Membranes & $\begin{array}{l}\text { Pore size } \\
(\mathrm{nm})\end{array}$ & Gas mixture & $\begin{array}{l}\text { Temperature } \\
(\mathrm{K})\end{array}$ & $\begin{array}{l}\text { Feed pressure } \\
\text { (bar) }\end{array}$ & $\begin{array}{l}\mathrm{CO}_{2} \text { permeance } \\
\left(10^{-7} \mathrm{~mol} \mathrm{~m}^{-2} \mathrm{~s}^{-1} \mathrm{~Pa}^{-1}\right)\end{array}$ & $\begin{array}{l}\text { Separation } \\
\text { selectivity } \\
\text { (factor) }\end{array}$ & References \\
\hline MFI & 0.55 & $\mathrm{CO}_{2} / \mathrm{H}_{2}$ & 290 & 9 & 78 & 37 & Our previous work ${ }^{16}$ \\
\hline MFI & 0.55 & $\mathrm{CO}_{2} / \mathrm{H}_{2}$ & 298 & 3.3 & 1.2 & $10^{a}$ & 27 \\
\hline Silicalite-1 & 0.55 & $\mathrm{CO}_{2} / \mathrm{H}_{2}$ & 298 & 1 & 12 & $3.4^{a}$ & 28 \\
\hline SSZ-13 & 0.37 & $\mathrm{CO}_{2} / \mathrm{CH}_{4}$ & 293 & 6 & 3 & 42 & 31 \\
\hline SSZ-13 & 0.37 & $\mathrm{CO}_{2} / \mathrm{CH}_{4}$ & 293 & 2.7 & 2.6 & 95 & 32 \\
\hline SAPO-34 & 0.37 & $\mathrm{CO}_{2} / \mathrm{CH}_{4}$ & 293 & 1.2 & 25 & 9 & 33 \\
\hline CHA & 0.37 & $\mathrm{CO}_{2} / \mathrm{CH}_{4}$ & 293 & 9 & 78 & 32 & Present work \\
\hline
\end{tabular}

${ }^{a}$ Separation factor.
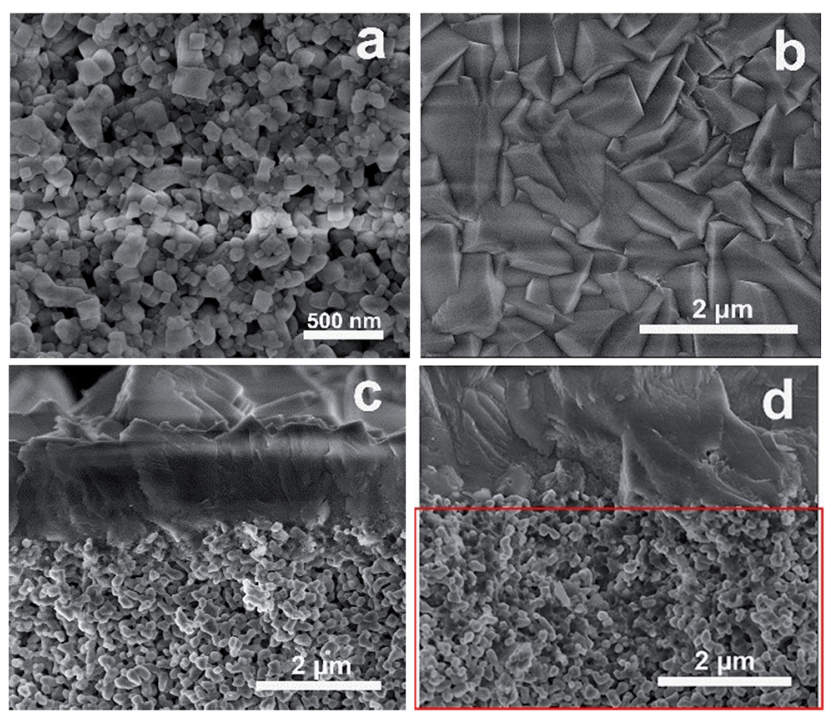

Fig. 7 SEM images of the Si-CHA seed layer (a), top-view (b) and cross-section (c) of an as-synthesised CHA membrane and the membrane prepared from a non-masked support (d).

different batches, displayed negligible helium permeance in the range of 0.005 to $0.01 \times 10^{-7} \mathrm{~mol} \mathrm{~m}^{-2} \mathrm{~s}^{-1} \mathrm{~Pa}^{-1}$. Such a low permeance indicates that the membranes should be essentially free from defects. The top-view SEM image (Fig. 7b) shows that the film is continuous and is composed of well intergrown zeolite crystals at the top surface of the membrane. No defects in the membrane could be observed by SEM. Images of the cross-section showed a rather even film with a thickness less than $1.5 \mu \mathrm{m}$ (Fig. 7c). Moreover, no invasion of the support pores could be observed. Conversely, Fig. $7 \mathrm{~d}$ in the ESI $\dagger$ demonstrates that a CHA membrane prepared without masking clearly resulted in an invaded support (red framed area). Consequently, the results indicated that the masking method described is efficient for avoiding invasion of the $\alpha$-alumina support during synthesis of the CHA membranes.

Separation of an equimolar mixture of $\mathrm{CO}_{2} / \mathrm{CH}_{4}$ using the prepared CHA disc membrane showed a separation selectivity of 32 and a very high $\mathrm{CO}_{2}$ permeance of $78 \times 10^{-7} \mathrm{~mol} \mathrm{~m}^{-2} \mathrm{~s}^{-1}$ $\mathrm{Pa}^{-1}$ at 9 bar feed pressure and room temperature. Even better separation performance was observed at $249 \mathrm{~K}$ with a very high $\mathrm{CO}_{2}$ permeance of $79 \times 10^{-7} \mathrm{~mol} \mathrm{~m}^{-2} \mathrm{~s}^{-1} \mathrm{~Pa}^{-1}$ and a $\mathrm{CO}_{2} / \mathrm{CH}_{4}$ separation selectivity of 76 . Normally, the reported permeances of $\mathrm{CO}_{2}$ for Si-CHA type membranes (SSZ-13) are lower than $3 \times$ $10^{-7} \mathrm{~mol} \mathrm{~m}^{-2} \mathrm{~s}^{-1} \mathrm{~Pa}^{-1}$ at room temperature, ${ }^{31,32,38}$ while we observed a more than 26 times higher $\mathrm{CO}_{2}$ permeance. The very high permeance of the CHA membrane observed here was certainly a result of the thin film supported on a non-invaded graded support. The results also indicated the applicability of the new method developed.

The developed method was also employed to prepare tubular MFI and CHA membranes to demonstrate the wide applicability. Briefly, the tubular MFI membranes display an almost equally high single gas helium permeance of $73 \times 10^{-7} \mathrm{~mol}$ $\mathrm{m}^{-2} \mathrm{~s}^{-1} \mathrm{~Pa}^{-1}$. Furthermore, the permporometry patterns (Fig. S1 in the ESI $\dagger$ ) showed that the helium permeance could be reduced to $0.24 \times 10^{-7} \mathrm{~mol} \mathrm{~m}^{-2} \mathrm{~s}^{-1} \mathrm{~Pa}^{-1}$, i.e. a decrease by $99.6 \%$ when the relative pressure of $n$-hexane increased to 0.023 and the zeolite pores and micropore defects $(<1.03 \mathrm{~nm})$ were blocked. When the relative pressure of $n$-hexane was further increased to 0.9 , the helium permeance decreased to $0.02 \%$ of the initial permeance. This indicates that the membrane is of very high quality with no large defects. As for discs, the single gas permeances of the tubular CHA membranes were also determined before and after calcination. The tubular CHA membranes showed negligible helium permeances before calcination, which indicated that the membranes should be essentially free from defects. After calcination, an average He permeance of $32 \times 10^{-7}$ mol m${ }^{-2} \mathrm{~s}^{-1} \mathrm{~Pa}^{-1}$ was obtained. In addition, an average $\mathrm{H}_{2}$ permeance of $80 \times 10^{-7} \mathrm{~mol} \mathrm{~m}^{-2} \mathrm{~s}^{-1} \mathrm{~Pa}^{-1}$ and an average $\mathrm{CO}_{2}$ permeance of as high as $127 \times 10^{-7} \mathrm{~mol} \mathrm{~m}^{-2} \mathrm{~s}^{-1} \mathrm{~Pa}^{-1}$ were obtained for the tubular CHA membranes. More single gas permeation data for quality evaluation of tubular CHA membranes can be found in the ESI (Table S1). $\dagger$ Separation of an equimolar mixture of $\mathrm{CO}_{2} / \mathrm{CH}_{4}$ using the prepared tubular CHA membranes showed a $\mathrm{CO}_{2}$ separation selectivity of 46 and $\mathrm{CO}_{2}$ permeance of $40 \times 10^{-7} \mathrm{~mol} \mathrm{~m}^{-2} \mathrm{~s}^{-1} \mathrm{~Pa}^{-1}$ at 9 bar feed pressure and room 
temperature, which indicated a high quality membrane. All of the results indicate the wide applicability of the method.

\section{Conclusions}

In the present work, a novel method for the preparation of high quality and high flux zeolite membranes was described in detail for the first time. Invasion of the support could be minimized efficiently by making the support hydrophobic. Accordingly, the present masking method is suitable for all support materials exhibiting hydroxyl functions on their surface. The synthesized membranes showed excellent separation performance. In addition, the method is easy to apply and allows preparation of membranes with arbitrary geometry.

\section{Conflicts of interest}

There are no conflicts to declare.

\section{Acknowledgements}

The Swedish Research Council for Environment, Agricultural Sciences and Spatial Planning Formas, the Swedish Energy Agency, and Bio4Energy (a strategic research environment appointed by the Swedish government) are gratefully acknowledged for financial support.

\section{Notes and references}

1 M. Zhou, D. Korelskiy, P. Ye, M. Grahn and J. Hedlund, Angew. Chem., Int. Ed., 2014, 53, 3492-3495.

2 L. Sandström, E. Sjöberg and J. Hedlund, J. Membr. Sci., 2011, 380, 232-240.

3 D. Korelskiy, M. Grahn, P. Ye, M. Zhou and J. Hedlund, $R S C$ Adv., 2016, 6, 65475-65482.

4 M. A. Carreon, S. Li, J. L. Falconer and R. D. Noble, J. Am. Chem. Soc., 2008, 130, 5412-5413.

5 J. Shang, G. Li, R. Singh, Q. Gu, K. M. Nairn, T. J. Bastow, N. Medhekar, C. M. Doherty, A. J. Hill, J. Z. Liu and P. A. Webley, J. Am. Chem. Soc., 2012, 134, 19246-19253.

6 S. Li, J. L. Falconer and R. D. Noble, Adv. Mater., 2006, 18, 2601-2603.

7 L. Yu, A. Holmgren, M. Zhou and J. Hedlund, J. Mater. Chem. A, 2018, 6, 6847-6853.

8 N. Kosinov, C. Auffret, G. J. Borghuis, V. G. P. Sripathi and E. J. M. Hensen, J. Membr. Sci., 2015, 484, 140-145.

9 S. Li, J. L. Falconer and R. D. Noble, Microporous Mesoporous Mater., 2008, 110, 310-317.

10 J. Jiang, X. Wang, Y. Zhang, D. Liu and X. Gu, Microporous Mesoporous Mater., 2015, 215, 98-108.

11 Y. Zheng, N. Hu, H. Wang, N. Bu, F. Zhang and R. Zhou, J. Membr. Sci., 2015, 475, 303-310.

12 H. Kalipcilar, T. C. Bowen, R. D. Noble and J. L. Falconer, Chem. Mater., 2002, 14, 3458-3464.

13 Y. Hasegawa, T. Tanaka, K. Watanabe, B. H. Jeong, K. Kusakabe and S. Morooka, Korean J. Chem. Eng., 2002, 19, 309-313.
14 J. C. Poshusta, R. D. Noble and J. L. Falconer, J. Membr. Sci., 1999, 160, 115-125.

15 J. Lindmark and J. Hedlund, J. Mater. Chem., 2010, 20, 22192225.

16 D. Korelskiy, P. Ye, S. Fouladvand, S. Karimi, E. Sjöberg and J. Hedlund, J. Mater. Chem. A, 2015, 3, 12500-12506.

17 J. Hedlund, J. Sterte, M. Anthonis, A. J. Bons, B. Carstensen, N. Corcoran, D. Cox, H. Deckman, W. de Gijnst, P. P. de Moor, F. Lai, J. McHenry, W. Mortier and J. Reinoso, Microporous Mesoporous Mater., 2002, 52, 179-189.

$18 \mathrm{~J}$. Hedlund, F. Jareman, A. J. Bons and M. Anthonis, J. Membr. Sci., 2003, 222, 163-179.

19 L. Sandström, J. Lindmark and J. Hedlund, J. Membr. Sci., 2010, 360, 265-275.

20 D. Korelskiy, T. Leppäjärvi, H. Zhou, M. Grahn, J. Tanskanen and J. Hedlund, J. Membr. Sci., 2013, 427, 381-389.

21 L. Yu, D. Korelskiy, M. Grahn and J. Hedlund, Sep. Purif. Technol., 2015, 153, 138-145.

22 L. Yu, M. Grahn, P. Ye and J. Hedlund, J. Membr. Sci., 2017, 524, 428-435.

23 L. Yu, M. Grahn and J. Hedlund, J. Membr. Sci., 2018, 551, 254-260.

24 Y. Yan, M. E. Davis and G. R. Gavalas, J. Membr. Sci., 1997, 126, 53-65.

25 J. Hedlund, D. Korelskiy, L. Sandström and J. Lindmark, J. Membr. Sci., 2009, 345, 276-287.

26 D. Korelskiy, M. Grahn, J. Mouzon and J. Hedlund, J. Membr. Sci., 2012, 417-418, 183-192.

27 A. Alshebani, M. Pera-Titus, E. Landrivon, T. Schiestel, S. Miachon and J.-A. Dalmon, Microporous Mesoporous Mater., 2008, 115, 197-205.

28 J. Lindmark and J. Hedlund, J. Mater. Chem., 2010, 20, 22192225.

29 K. Kusakabe, T. Kuroda, K. Uchino, Y. Hasegawa and S. Morooka, AIChE J., 1999, 45, 1220-1226.

30 X. Zhu, H. Wang and Y. S. Lin, Ind. Eng. Chem. Res., 2010, 49, 10026-10033.

31 N. Kosinov, C. Auffret, C. Gücüyener, B. M. Szyja, J. Gascon, F. Kapteijn and E. J. M. Hensen, J. Mater. Chem. A, 2014, 2, 13083-13092.

32 T. Wu, M. C. Diaz, Y. Zheng, R. Zhou, H. H. Funke, J. L. Falconer and R. D. Noble, J. Membr. Sci., 2015, 473, 201-209.

33 Y. Tian, L. Fan, Z. Wang, S. Qiu and G. Zhu, J. Mater. Chem., 2009, 19, 7698-7703.

34 J. Albo, J. Wang and T. Tsuru, J. Membr. Sci., 2014, 453, 384393.

35 J. Albo, J. Wang and T. Tsuru, J. Membr. Sci., 2014, 449, 109118.

36 J. Albo, H. Hagiwara, H. Yanagishita, K. Ito and T. Tsuru, Ind. Eng. Chem. Res., 2014, 53, 1442-1451.

37 M. Zhou and J. Hedlund, Angew. Chem., Int. Ed., 2018, 57, 10966-10970.

38 E. Jang, S. Hong, E. Kim, N. Choi, S. J. Cho and J. Choi, J. Membr. Sci., 2018, 549, 46-59. 